\title{
MAPEAMENTO SOBRE A EXPERIÊNCIA PRÉVIA COM DESIGN CENTRADO NO USUÁRIO (DCU) DE DESENVOLVEDORES DE SISTEMAS E-GOV
}

\section{MAPPING ON PREVIOUS EXPERIENCE WITH USER-CENTERED DESIGN (UCD) FROM E-GOV SYSTEM DEVELOPERS}

\author{
André Schlemmer ${ }^{1}, \mathrm{M}$. Sc. \\ schlemmer.andre@gmail.com e http://orcid.org/0000-0002-0819-7800 \\ Stephania Padovani ${ }^{1}$, D. Sc. \\ stephania.padovani@gmail.com e http://orcid.org/0000-0002-3051-8949 \\ ${ }^{1}$ Universidade Federal do Paraná, Programa de Pós-Graduação em Design, Curitiba, Brasil
}

processo de desenvolvimento de sistemas, design centrado no usuário, desenvolvedor de sistemas, pesquisa-ação

A nova economia favoreceu a expansão das tecnologias da informação e comunicação, em cuja progressão surgiram os sistemas e-Gov. O e-Gov pretende fornecer os serviços do governo com melhores resultados e qualidades aos cidadãos, mas por que alguns desses sistemas ainda falham? O estudo propõe mapear as experiências prévias dos desenvolvedores perante o design centrado no usuário (DCU) durante o processo de desenvolvimento de sistemas (PDS). Para tanto, utilizou-se do método da Pesquisa-Ação. O procedimento de coleta de dados está relacionado com a primeira ação, que foi um questionário online e obteve 122 respondentes. Os principais achados condizem com a falta de conhecimento ou de treinamento dos desenvolvedores sobre a abordagem do DCU. Além disso, aspectos como a falta de uma comunicação clara e precisa, implementação do sistema, tempo hábil e acúmulo de papéis podem ser fatores para não utilizar a abordagem do DCU durante o PDS da organização investigada.

systems development process, user-centered design / user-centric design, systems developer, action research

The new economy has favored the expansion of information and communication technologies, in whose progression eGov systems have emerged. The e-Gov intends to provide government services with better results and quality to citizens, but why do some of these systems still fail? The study proposes to map developers' prior experiences in relation to user-centered design (UCD) during the system development process (SDP), for this, the Action Research method was used. The data collection procedure is related to first action, which was an online questionnaire and obtained 122 respondents. The main findings match with developers' lack of knowledge or training about UCD approach. In addition, aspects such as lack of clear and precise communication, system implementation, lack of time and accumulation of roles may be factors for not using UCD approach during the SDP of investigated organization. 


\section{Introdução}

Em uma perspectiva voltada ao impacto que a nova economia causou na sociedade, trazendo consideráveis transformações na produção de bens e serviços, as tecnologias da informação e comunicação (TICs) ganharam espaço. Uma dessas transformações está situada no governo, estabelecendo o termo e-Gov (governo eletrônico), o qual busca fornecer melhores resultados e qualidade em sua política comunicacional e seus serviços, para proporcionar engajamento e participação dos cidadãos (ARGANDOÑA, 2003; OECD, 2003).

Entretanto, ainda existem barreiras/dificuldades para aproximar a abordagem do design centrado no usuário (DCU) com projetos de desenvolvimento de sistemas (PDS) e-Gov. No estudo de Sánchez-Torres e Miles (2017) sobre a análise de tecnologia orientada para o futuro, além de verificarem o baixo nível de envolvimento de cidadãos com o e-Gov, os autores recomendam que se investiguem os motivos e maneiras para melhorar o engajamento e a compreensão das demandas dos cidadãos.

Em estudos do e-Gov brasileiro, houve avaliações e análises em determinados sites/portais públicos, que resultaram na ineficiência da facilidade de uso, da qualidade informacional, na falta de recursos, na dificuldade em compreender termos e limitações na utilização do sistema (DAMIAN E MERLO, 2013; DE MELO E GOMES, 2016). Além disso, nos estudos de Freire e Batista (2016) e Judice et al. (2019), nos quais houve o envolvimento dos usuários durante a coleta de dados, os resultados também identificaram limitações e obstáculos perante a quantidade de informações, ilegibilidade de conteúdo, falhas no comando de recursos e dificuldades referentes a arquitetura de informação e navegação.

Portanto, o presente artigo é um recorte de um projeto de pesquisa que busca a aproximação da área do Design com o desenvolvimento de sistemas e-Gov, especificamente, desenvolver ações para inserir práticas do DCU durante o PDS e-Gov.

A concretização do objetivo deste artigo aplica-se através do método da pesquisa-ação (PA). Durante o primeiro plano de ação, os integrantes da PA definiram como primeira ação realizar um mapeamento das experiências prévias dos desenvolvedores da Companhia de Tecnologia da Informação e Comunicação do Paraná (CELEPAR) por intermédio de um questionário online.

\section{Processo de desenvolvimento de sistemas (PDS)}

Para Sommerville (2016), o PDS pode ser definido como um conjunto de atividades que resultam na produção de um produto de software, a saber:

- Especificações (aspectos da funcionalidade e restrições);

- Desenvolvimento (produção do software de acordo com as especificações definidas);

- Validação (garantir e verificar as exigências do cliente);

- Evolução (o software é modificado para atender os requisitos do cliente e do mercado).

Além disso, através da revisão de literatura também foi possível identificar que existem alguns métodos de desenvolvimento aplicáveis no PDS:

- Prescritivo - segundo Pressman e Maxim (2015, p. 42) é "um conjunto prescrito de elementos de processo e um fluxo de trabalho previsível", ou seja, a ordem e a consistência do projeto são determinantes nesse método;

- Ágil - o método de desenvolvimento rápido é concebido por uma série de versões (incremental), suas características estão na intercalação entre especificações, projeto e implementação, os usuários 
finais e outros stakeholders do sistema estão envolvidos fornecendo feedbacks, foco nas habilidades da equipe, na aceitação das mudanças durante o método e esforços dos envolvidos para eliminar as complexidades durante o PDS (SOMMERVILLE, 2016).

Outra característica presente no PDS condiz com os fatores essenciais para a melhoria do processo, Pressman e Maxim (2015) citam alguns exemplos:

- A gerência precisa ter um envolvimento ativo, comprometimento com a gestão e prover suporte;

- A equipe de projeto deve estar envolvida em todo o processo de melhoria;

- O processo de melhoria deve ser compreendido como parte integrante da cultura organizacional e de outros processos internos;

- As estratégias de melhoria precisam ser adaptadas conforme a realidade da organização, bem como, ter um gerenciamento ativo e eficaz.

\section{Design Centrado no Usuário (DCU)}

O termo Design Centrado no Usuário (DCU) teve sua origem no livro "User Centered System Design: New Perspectives on Human-Computer Interaction" de Norman e Draper (1986). No capítulo três desse livro, os autores relatam sobre a importância de desenvolver os sistemas para as pessoas e não apenas focado na tecnologia, e então, deixam explicado que o objetivo do DCU é atender às necessidades do usuário.

Prosseguindo com seus estudos, em Norman (2006, p. 222), o autor amplia os conhecimentos sobre o termo, e relata que o DCU é uma abordagem baseada nas necessidades e interesses do usuário, ou seja, deve "assegurar que (1) o usuário pode descobrir o que fazer, e (2) que tenha condições de saber o que está acontecendo".

Da NBR ISO 9241-210 (ABNT, 2011), pode ser feito uma relação do termo DCU com o desenvolvimento de sistemas interativos e que a norma denomina sendo "projeto centrado no ser humano", pois além dos usuários finais também são considerados os demais stakeholders. Mas, o foco continua mantido nas necessidades e exigências dos usuários para resultarem em sistemas utilizáveis e úteis.

Além da conceituação, existem princípios-chave para guiar e facilitar o desenvolvimento, a comunicação e a avaliação de projetos com abordagem em DCU, dessa forma, apresenta-se no quadro 01 um quadro teórico comparando as semelhanças e diferenças dos princípios-chave.

\begin{tabular}{|c|l|}
\hline Autores & SEMELHANÇAS \\
\hline $1|2| 3$ & $\begin{array}{l}\text { Entendimento do usuário, } \\
\text { das tarefas e do ambiente }\end{array}$ \\
\hline $1|2| 3$ & $\begin{array}{l}\text { Processo de } \\
\text { desenvolvimento é iterativo }\end{array}$ \\
\hline $1|2| 3$ & $\begin{array}{l}\text { Avaliar o projeto com os } \\
\text { usuários antes de se tornar } \\
\text { um produto definitivo/final }\end{array}$ \\
\hline $1 \mid 2$ & $\begin{array}{l}\text { Utilização de simulações e } \\
\text { protótipos para interação } \\
\text { com os usuários nas fases } \\
\text { iniciais do projeto }\end{array}$ \\
\hline $2 \mid 3$ & $\begin{array}{l}\text { Envolvimento ativo do } \\
\text { usuário durante todo o } \\
\text { processo de } \\
\text { desenvolvimento }\end{array}$ \\
\hline
\end{tabular}

\begin{tabular}{|c|l|}
\hline Autores & DIFERENÇAS \\
\hline 2 & $\begin{array}{l}\text { Especificar metas de usabilidade e critérios de design para situações gerais } \\
\text { de uso durante as interações com usuários }\end{array}$ \\
\hline 2 & $\begin{array}{l}\text { Disponibilizar ferramentas para facilitar a cooperação e a eficiência da } \\
\text { equipe de projeto }\end{array}$ \\
\hline 2 & $\begin{array}{l}\text { Representações de design e terminologias precisam ser utilizáveis e } \\
\text { eficazes para que todos os envolvidos consigam facilmente compreender }\end{array}$ \\
\hline 2 & $\begin{array}{l}\text { As atividades condizentes com o design (por exemplo, interface, interações } \\
\text { e usabilidade) precisam ser estruturadas, dedicadas e conscientes durante } \\
\text { o desenvolvimento do sistema, essas atividades serão explicitadas e } \\
\text { registradas (memória do processo) }\end{array}$ \\
\hline 2 & $\begin{array}{l}\text { Envolvimento de um especialista em usabilidade, que terá autoridade para } \\
\text { decidir as situações relacionadas com a usabilidade do sistema e de uso } \\
\text { futuro }\end{array}$ \\
\hline
\end{tabular}




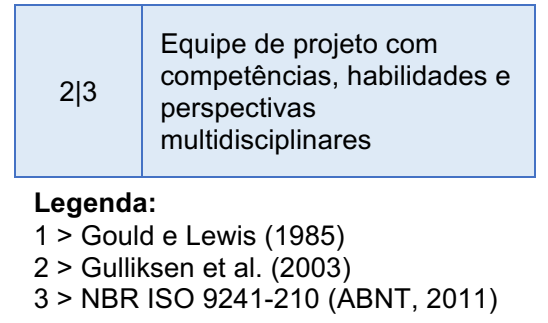

\begin{tabular}{|c|c|}
\hline 2 & $\begin{array}{l}\text { Em paralelo ao PDS, deve ser desenvolvido todos os aspectos que } \\
\text { influenciam a situação de uso futuro do software (por exemplo, práticas e } \\
\text { organização do trabalho, manuais de uso, ajuda online, treinamento do } \\
\text { usuário, contexto de uso, aspectos de saúde e segurança, etc.), para obter } \\
\text { um processo de design integrado }\end{array}$ \\
\hline 2 & $\begin{array}{l}\text { O processo, os métodos, a ordem das atividades, técnicas, entre outros, } \\
\text { devem ser especificados, adaptados e/ou implementados de acordo com } \\
\text { as situações reais da organização em que se realiza o PDS, porém devem } \\
\text { estar de acordo com os princípios-chave do DCU }\end{array}$ \\
\hline 2 & $\begin{array}{l}\text { Os envolvidos no projeto devem estar cientes e comprometidos com a } \\
\text { importância da usabilidade e o envolvimento do usuário }\end{array}$ \\
\hline 3 & $\begin{array}{l}\text { Identificar e considerar os stakeholders, ou seja, todos os afetados (direta } \\
\text { ou indiretamente) pelo uso do sistema }\end{array}$ \\
\hline 3 & $\begin{array}{l}\text { Além das funcionalidades e desempenho do sistema, é preciso incluir } \\
\text { questões sobre os aspectos perceptivos e emocionais dos usuários (por } \\
\text { exemplo, atitudes, habilidades, hábitos, expectativas, entre outros), bem } \\
\text { como, considerar as experiências anteriores dos usuários com outros } \\
\text { sistemas e a integração do projeto como um todo, desde suporte e apoio } \\
\text { ao usuário até o impacto organizacional, manutenção, treinamento, etc. }\end{array}$ \\
\hline
\end{tabular}

Quadro 01: Quadro teórico dos princípios-chave do DCU

Fonte: Os autores (2020)

No que se refere as iniciativas de envolvimento do usuário, Krinner (2007) dividiu em três níveis: (1) para o usuário, aplicando os princípios de projeto centrado no usuário; (2) com o usuário, aplicando métodos de design participativo; e (3) pelo usuário, a equipe de projeto disponibiliza componentes pré-definidos para o usuário manipular, organizar conforme o objetivo estabelecido e de acordo com a sua percepção.

Outra maneira de envolvimento do usuário foi apresentada nos estudos de Cybis, Betiol e Faust (2015), Damodaran (1996) e Muller e Druin (2012). De forma sintetizada, existem três níveis: (1) informativo, nível básico, em que o usuário fornece ou recebe informações; (2) consultivo, a equipe de projeto solicita aos usuários que avaliem e forneçam suas opiniões perante as soluções propostas; (3) participativo, nível que requer um esforço maior, pois o usuário influencia e também exerce o poder de decisões no projeto.

\section{Governo eletrônico (e-Gov)}

O termo governo eletrônico (e-Gov), no sentido de mudança organizacional e estratégica dos governos para fornecerem serviços ao cidadão através das TICs, iniciou-se no final dos anos 90. Existem diversas definições, porém as que prevalecem condizem com a relação governo-cidadão no campo de práticas, com o intuito de alcançar êxito por meio do uso da tecnologia (GRÖNLUND E HORAN, 2005).

Ainda sobre as definições do e-Gov, Grönlund (2002) explica que os conceitos estão envolvidos por eficiência (racionalização), qualidade (dos serviços) e democracia (participação pública), e com diferentes focos que podem enfatizar atribuições econômicas, emancipatórias e de serviços.

No Brasil, o conceito de e-Gov foi expandido para governança digital, que mantém a informatização dos serviços prestados pelo governo para a sociedade, porém com a inclusão da participação do cidadão na construção de políticas públicas através de plataformas digitais (BRASIL, 2018).

Além dos conceitos, outro aspecto relevante do e-Gov é compreender as relações e combinações complexas de fatores e dimensões que afetam o PDS deste segmento. Algumas dimensões são exemplificadas em CGI.br (2016), tais como aspectos legais e políticos, recursos humanos e infraestrutura.

Estas dimensões estão atreladas tanto a concepção quanto a atualização de sistemas e-Gov, e através das relações entre essas dimensões são elaborados os modelos organizacionais públicos, pelos quais determinam

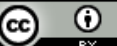


objetivos que vão gerar valores públicos e novas bases de e-Gov, consequentemente, por questões tecnológicas, são projetados os sistemas de informação (CGI.br, 2016).

A revisão de literatura proporcionou uma familiaridade com as atividades do PDS, o entendimento dos princípios-chave, técnicas e níveis de envolvimento dos usuários em uma abordagem de DCU, como também, a compreensão sobre e-Gov e suas dimensões que afetam e influenciam o PDS. Essas informações contribuirão para os pesquisadores elaborarem o instrumento de coleta que pretende mapear as experiências prévias dos desenvolvedores perante o DCU durante o PDS, além de servir como suporte teórico-conceitual para os pesquisadores durante as fases de desenvolvimento do projeto de pesquisa.

\section{Método}

A estruturação do método nesse estudo teve como base os autores Barbier (2007) - Educação, Coughlan e Coghlan (2002) - Administração, Thiollent (2011) - Sociologia, Tripp (2005) - Educação, Stringer (2007) Educação e Susman e Evered (1978) - Administração. O método definido é a Pesquisa-Ação (PA), segundo Thiollent (2011, p. 20) é "concebida e realizada em estreita associação com uma ação ou com a resolução de um problema coletivo e no qual os pesquisadores e os participantes representativos da situação ou do problema estão envolvidos de modo cooperativo ou participativo".

Através das leituras preliminares dos autores citados anteriormente, o método foi dividido em três fases: 1 Explorar, 2 - Agir e 3 - Finalizar. Além disso, existe uma mediação teórico-conceitual que pode ocorrer em qualquer uma das fases, caso seja necessário. A representação da estrutura pode ser observada na figura 01.

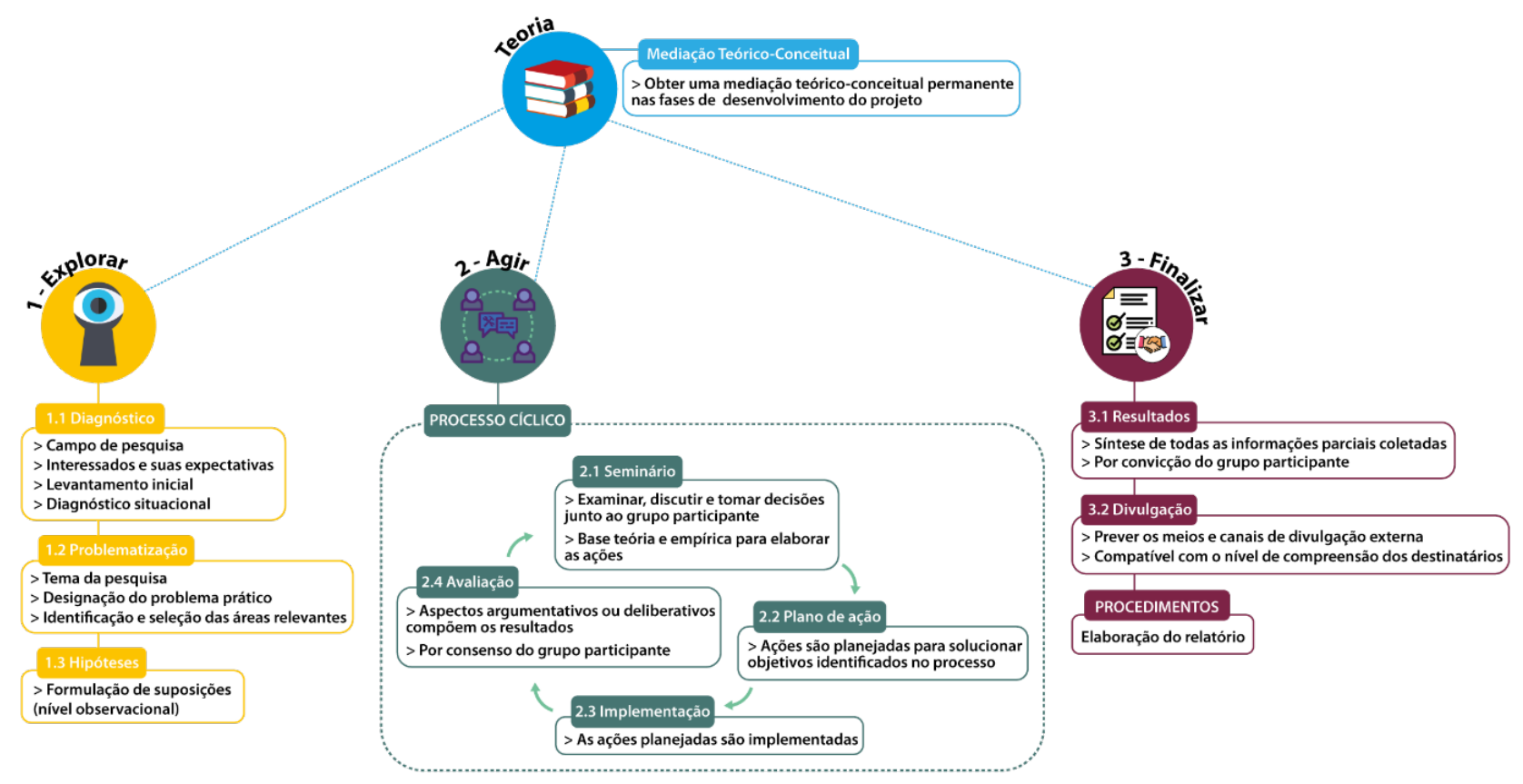

Figura 01: As fases da Pesquisa-Ação

Fonte: Os autores (2020)

Inicialmente, a gerente de sistemas de informação da organização trouxe aos pesquisadores uma demanda para ser investigada, dando início a fase Explorar da PA. Após elaborar o diagnóstico inicial feito pelos pesquisadores na organização e solicitar para a gerente indicar quais seriam os participantes representativos, formando assim os integrantes da PA ( 02 pesquisadores +02 gerentes +02 coordenadores de sistemas de informação + 02 analistas de sistemas - todos os participantes representativos fazem parte da diretoria de 
tecnologia), realizou-se o primeiro seminário pelo qual ocorreu a definição da problemática do projeto de pesquisa: como inserir práticas do DCU no PDS da organização?

Após a definição da problemática, os integrantes da PA elaboraram o planejamento da primeira ação (escopo do presente artigo): mapear as experiências prévias dos desenvolvedores em relação ao DCU durante o PDS. Para a realização, em comum acordo, os integrantes da PA optaram por um questionário online, no intuito de coletar informações de um número considerável de pessoas (aprox. 300 desenvolvedores) e pela agilidade em comunicar o instrumento internamente.

Para elaborar o questionário, os integrantes da PA atribuíram aos pesquisadores a função de realizar uma mediação teórico-conceitual. Os aspectos estudados na mediação teórico-conceitual condizem com as informações situacionais dos analistas da organização, sobre o PDS e as informações relativas ao DCU. No segundo seminário, os integrantes da PA refinaram o questionário, definiram prazo de resposta, forma de envio (Google Forms), e as respostas foram enviadas diretamente para os pesquisadores, de forma sigilosa.

A versão aprovada pelos integrantes da PA aborda os seguintes temas: dados específicos da organização setor, função e tempo de trabalho; principais etapas e fatores de sucesso no PDS; informações sobre quem vai usar o sistema; processo de avaliação, causas de ajuste e motivos de reclamações durante o PDS; e dados sobre o DCU - conceituação, motivos para utilizar ou não tal abordagem e formas de inserção no PDS.

O questionário online obteve 122 respondentes, o que corresponde a 40,6\% do total de aprox. 300 desenvolvedores. Sendo assim, este artigo apresenta os resultados coletados e as discussões da primeira ação realizada através do método da PA.

\section{Resultados e Discussão}

No sentido de entendimento das respostas, o questionário apresentava uma estrutura em que o respondente, na maior parte das questões, poderia selecionar mais de uma opção. Ao ler o termo cliente, entende-se como demandante, a pessoa que contratou o desenvolvimento do sistema (ex.: governo), os termos público-alvo, usuário, usuário final são destinados a quem vai utilizar o sistema (ex.: cidadãos), e o termo equipe é destinado aos colaboradores da organização que fazem parte da equipe de projeto (ex.: gerente do projeto, programadores, analistas de sistemas, etc).

As questões iniciais foram definidas para o levantamento de aspectos sobre acúmulo de papéis. A primeira questão era sobre o papel que os respondentes exercem, mostrado a seguir, no gráfico 01.

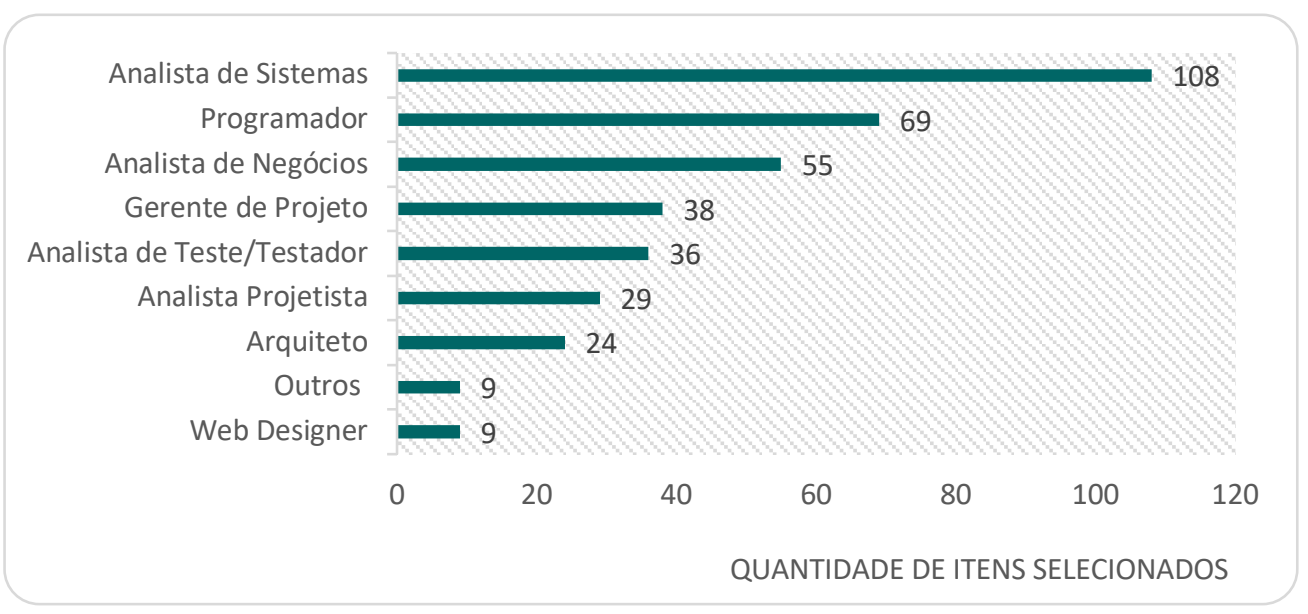

Gráfico 01: Papel que exerce na organização 
Fonte: Os autores (2020)

Para 108 respondentes, o principal papel que exercem é o de analisa de sistemas, seguido por programador (69) e analista de negócios (55). Dos desenvolvedores que responderam ao questionário, apenas 9 exercem o papel de web designer.

Das questões dos papéis, fica evidenciado que a maioria dos papéis selecionados pelos respondentes não estão atrelados a conhecimentos específicos de Design, de certa forma, a experiência prévia na área de Design pode colaborar na inserção das práticas de DCU durante o PDS. Ou então, segundo Lindberg, Meinel e Wagner (2011) que relatam os esforços para incluir especialistas em design que assumam o papel de "defensores do usuário" nas equipes de desenvolvimento, com isso, percebe-se a existência de uma lacuna de papel/função específica durante o PDS.

No gráfico 02, estão sintetizados os resultados sobre a quantidade de papéis que os desenvolvedores exercem na organização.

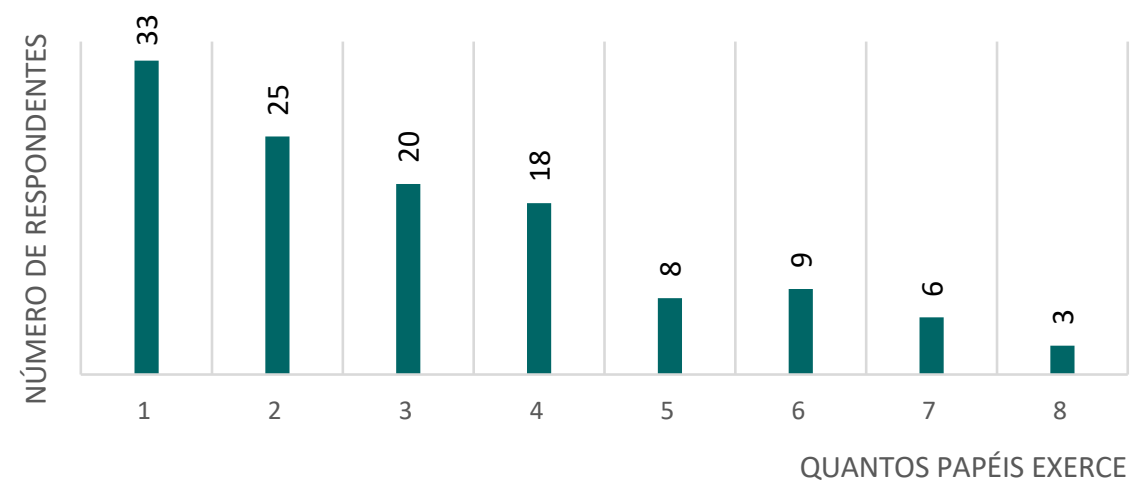

Gráfico 02: Acúmulo de papéis

Fonte: Os autores (2020)

A opção de exercer 1 papel foi selecionada por 33 respondentes, o item analista de sistemas foi selecionado por 22 e manteve-se como o papel mais selecionado no todo. 63 respondentes assumem de 2 a 4 papéis e acima de 4 papéis somam 26 respondentes.

Sobre a quantidade de papéis ou funções exercidas no dia a dia dos desenvolvedores, por intermédio de um dos seminário da PA destinado as discussões dos resultados deste questionário, os integrantes da PA, por um senso comum, concluíram que os desenvolvedores tendem a acumular papéis, inclusive o de testes sobre o sistema desenvolvido por eles mesmos, razão pela qual podem não focar em boas práticas ou utilizar o DCU.

Além de ser uma possível barreira para usar o DCU, o acúmulo de papéis proporcionou uma divisão de posicionamento entre os integrantes da PA. Para alguns integrantes é benéfico ter habilidades e práticas em diversos papéis, mas para outros consideram um empecilho. Uma possível solução sugerida durante a discussão pelos integrantes seria deixar explícito no projeto a definição e quantificação dos papéis, para obter um equilíbrio e o desenvolvedor não realizar vários papéis no mesmo projeto.

Sobre estes aspectos, Chevers e Grant (2017) relatam que as habilidades e a capacidade dos desenvolvedores em saber o que é necessário e o que deve ser feito é considerado como um fator crítico na qualidade do PDS. Jackman (1998) complementa a argumentação anterior destacando que se os papéis/funções não são claros durante o PDS pode ocasionar falhas, portanto, é necessário deixar claro a definição do papel exercido e não atribuir papéis errados, ou então, confrontar as pessoas que não cumprem seus papéis. Diante do exposto, é possível entender que o gerenciamento e controle das questões de definição e quantificação dos 
papéis/funções podem gerar falhas no projeto ou forçar os próprios desenvolvedores em cometer erros mais sérios durante o desenvolvimento de sistemas. A próxima questão se refere ao tempo de trabalho na organização (vide gráfico 03).

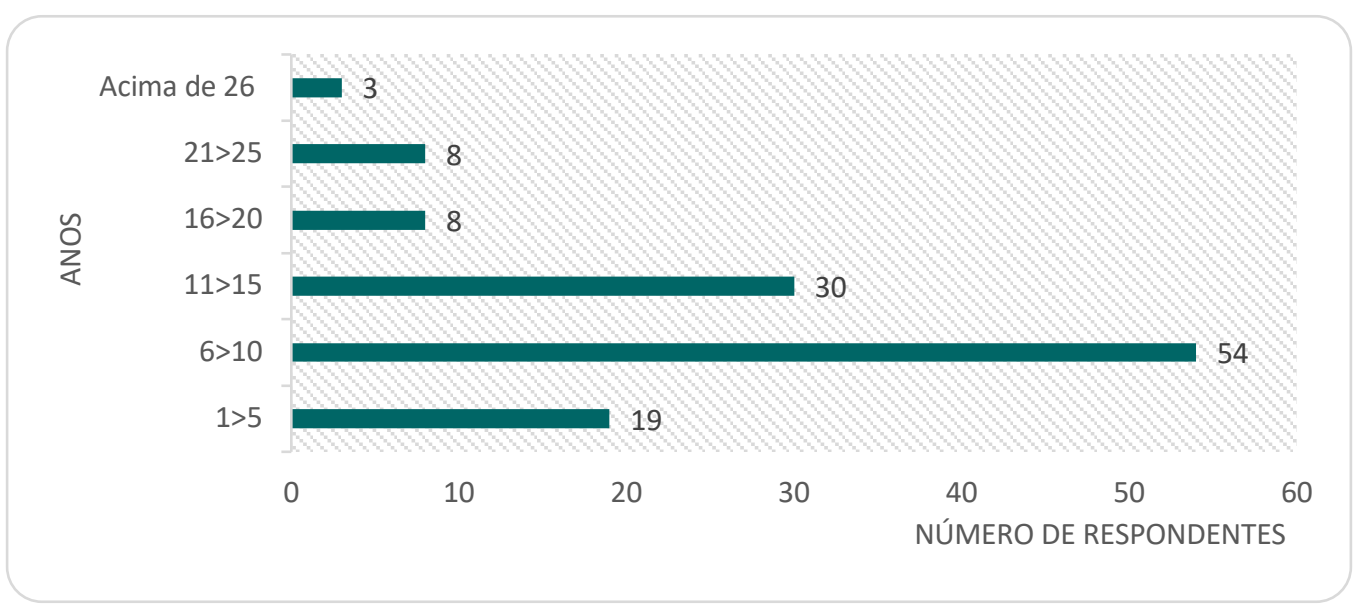

Gráfico 03: Tempo de trabalho

Fonte: Os autores (2020)

Sobre o tempo de trabalho, 54 respondentes trabalham de 6 a 10 anos. Na sequência, 30 trabalham entre 11 a 15 anos, 19 de 1 a 5 anos e acima de 16 anos apenas 19 respondentes.

Após ter um mapeamento de dados sobre os desenvolvedores, a sequência dos questionamentos aborda aspectos sobre o PDS e a correlação com o DCU. O gráfico 04 representa os resultados sobre o que determina o sucesso de um projeto/sustentação.

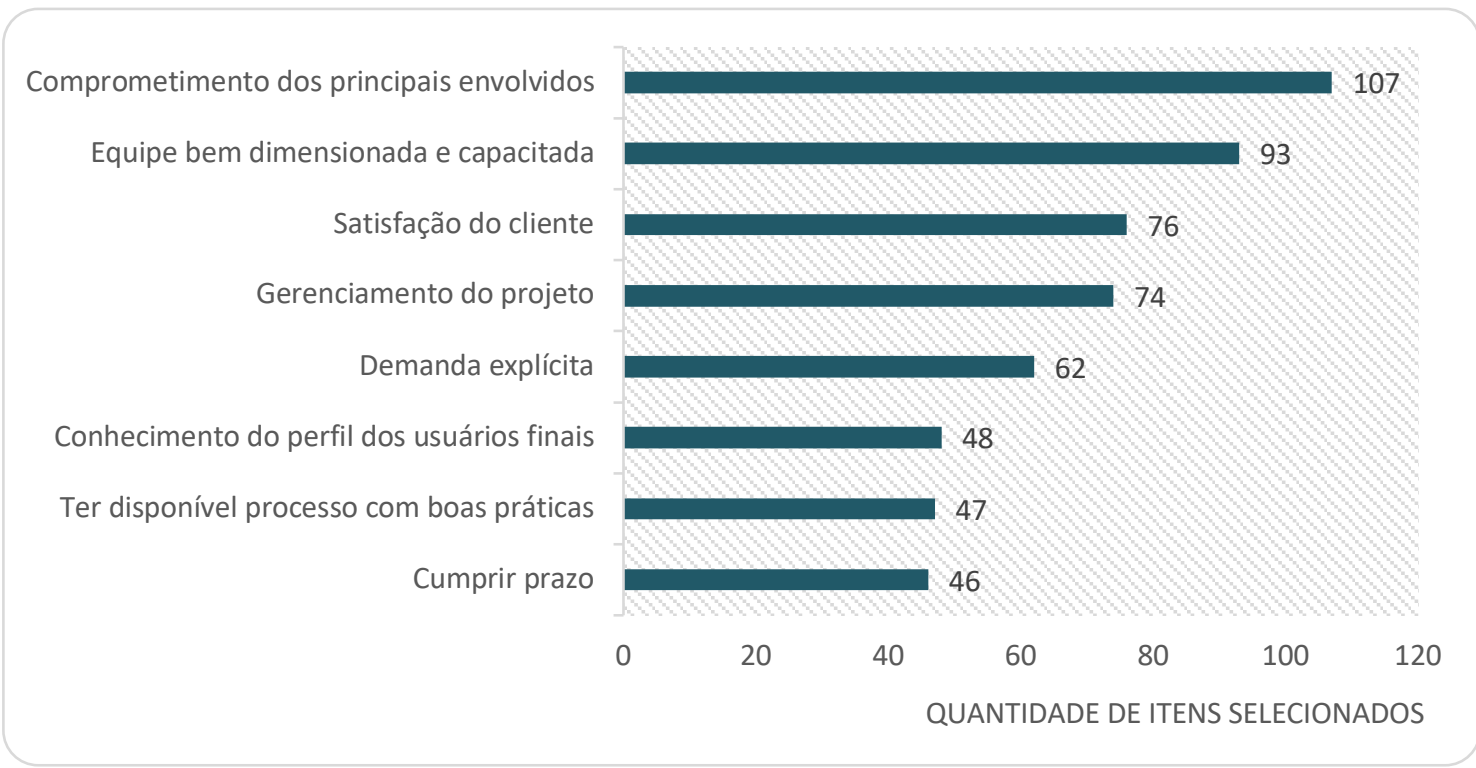

Gráfico 04: Sucesso de um projeto/sustentação

Fonte: Os autores (2020)

As opções mais selecionadas pelos respondentes condizem com competências e habilidades dos envolvidos no PDS, em contraste, o perfil dos usuários, as boas práticas e cumprir prazo tiveram poucas seleções. Na sequência, o gráfico 05 apresenta os resultados sobre a ferramenta de apoio, denominada de PDS, e disponível aos colaboradores da organização, o intuito era saber se os desenvolvedores utilizavam ou tinham conhecimento sobre a ferramenta de boas práticas. 


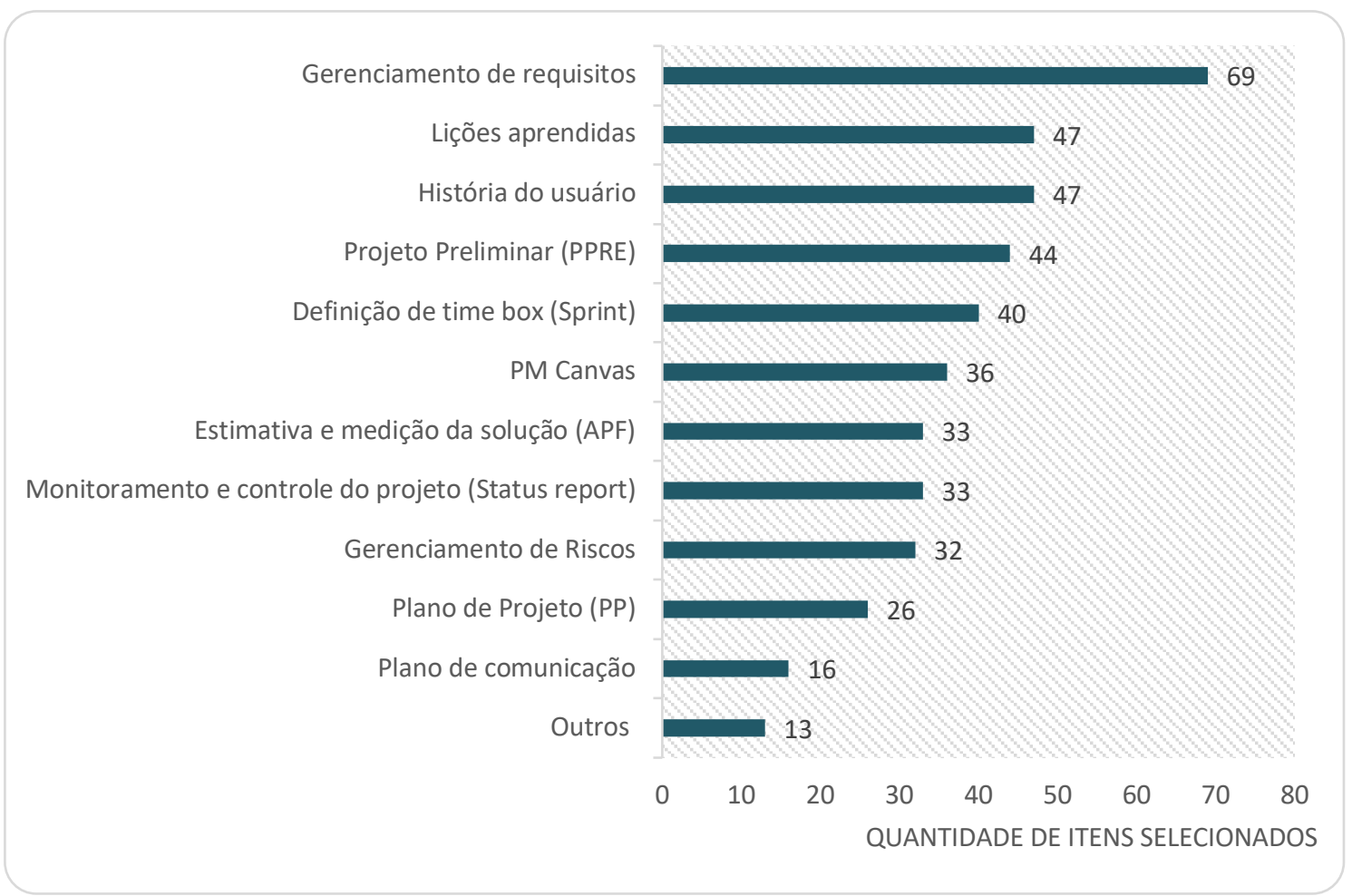

Gráfico 05: Utilização do PDS da CELEPAR (ferramenta de apoio)

Fonte: Os autores (2020)

O gerenciamento de requisitos foi a opção mais selecionada, porém as outras opções não chegaram a ser selecionadas nem pela metade dos respondentes. Da quantidade de itens selecionados da ferramenta de apoio, apenas 1 respondente assinalou os 11 itens na questão, a opção que teve mais seleção foi de 25 respondentes que selecionaram 3 dos 12 itens, e 23 escolheram apenas 1 item dos 12 apresentados na questão.

As respostas fornecidas pelos desenvolvedores sobre o PDS, o sucesso de um projeto/sustentação e a ferramenta de apoio trouxeram alguns apontamentos feitos pelos integrantes da PA durante um dos seminários. Um primeiro destaque é o cuidado em considerar as experiências do desenvolvedor em seu ambiente de trabalho. Além disso, houve a menção de não prevalecer como fator de sucesso as boas práticas e o cumprimento de prazos, pois nem a metade dos respondentes selecionaram essas duas opções.

Outro apontamento identificado condiz com a relevância em itens selecionados que apresentavam os termos requisitos - cliente - equipe. E ao analisar os resultados sobre a ferramenta de apoio, percebe-se que na prática, no trabalho do dia a dia os desenvolvedores não seguem um padrão, cada desenvolvedor determina como vai realizar o PDS, ou seja, o que existe são sugestões e boas práticas. A próxima questão era focada no atendimento da demanda (vide gráfico 06). 


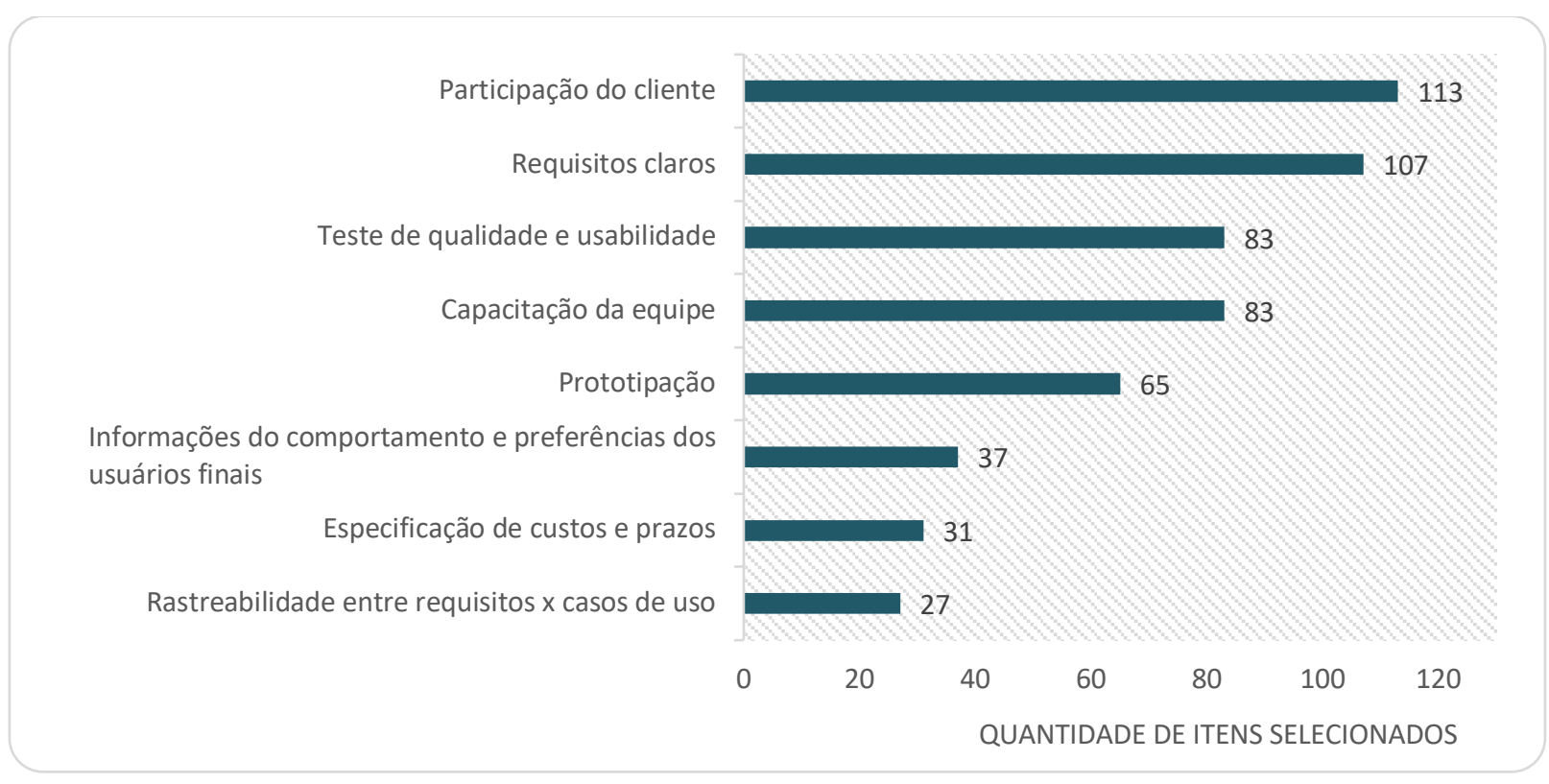

Gráfico 06: Importante para o atendimento da demanda Fonte: Os autores (2020)

O envolvimento do cliente foi selecionado por 113 respondentes, em contraste, apenas 37 selecionaram informações referentes ao usuário final.

Ao apresentar os resultados do atendimento da demanda houve uma ênfase na discussão entre os integrantes da PA sobre a capacitação da equipe, e como diversas respostas fornecidas pelos desenvolvedores envolviam o fator humano e o quanto a equipe estava preparada para executar o PDS. Sob estes aspectos, os integrantes da PA também manifestaram argumentos direcionados na dificuldade de ter uma equipe harmonizada e a falta de uma comunicação clara e precisa durante o PDS.

Ainda durante as discussões, foi averiguado que para 85 respondentes não é relevante ter informações do usuário final na etapa inicial, mas para os integrantes da PA é uma das formas de elaborar os requisitos e aplicar o DCU no PDS. A seguir, o gráfico 07 representa os resultados sobre o planejamento.

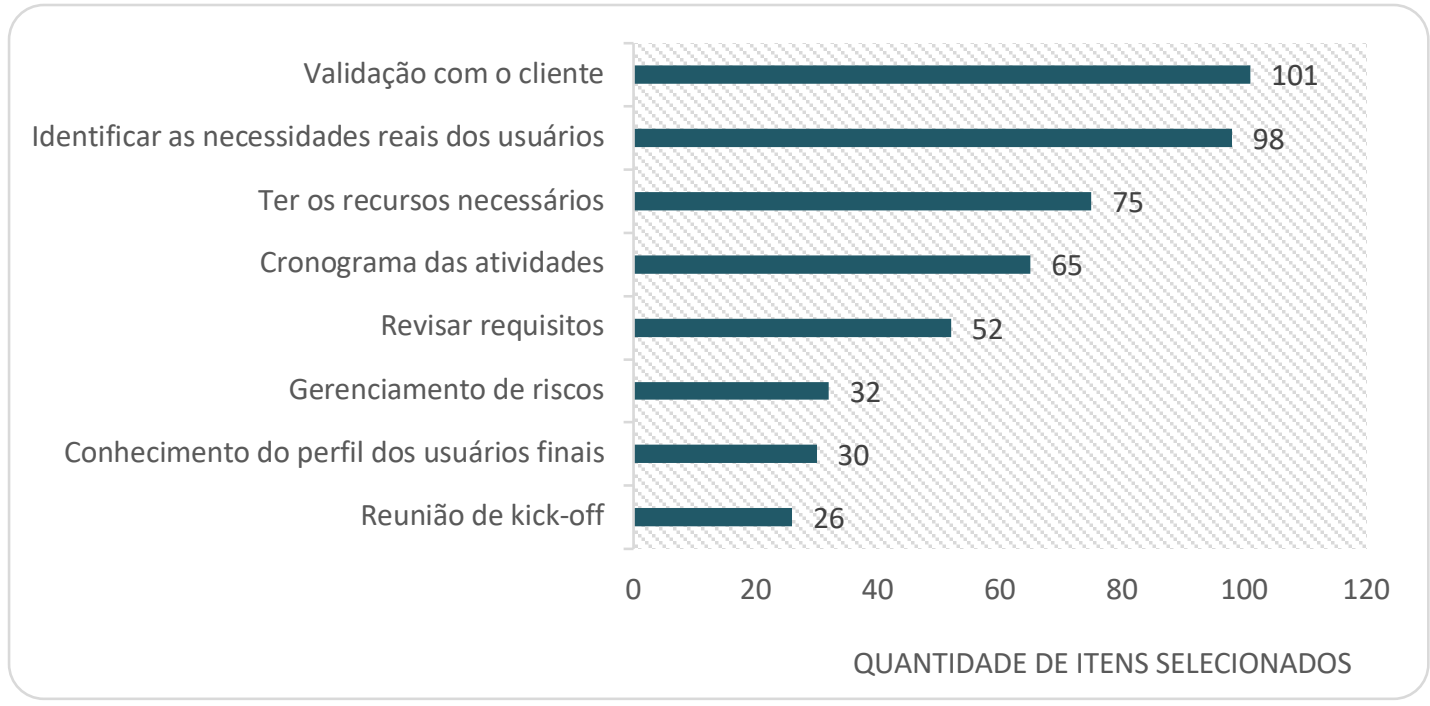

Gráfico 07: Importante para o planejamento do atendimento da demanda Fonte: Os autores (2020) 
No planejamento, 101 respondentes consideraram a validação com o cliente a opção mais relevante, muito próximo ficou a identificação das reais necessidades dos usuários. Mas, apenas 30 consideraram importante o perfil dos usuários finais, na interpretação feita pelos integrantes da PA, o termo perfil está correlacionado com a criação de atores ou categorias de usuários para serem utilizados, por exemplo, em casos de uso ou jornada de usuários, e com isso, não precisa necessariamente de dados reais do público-alvo. Os resultados do que é essencial durante a execução da demanda estão representados no gráfico 08 .

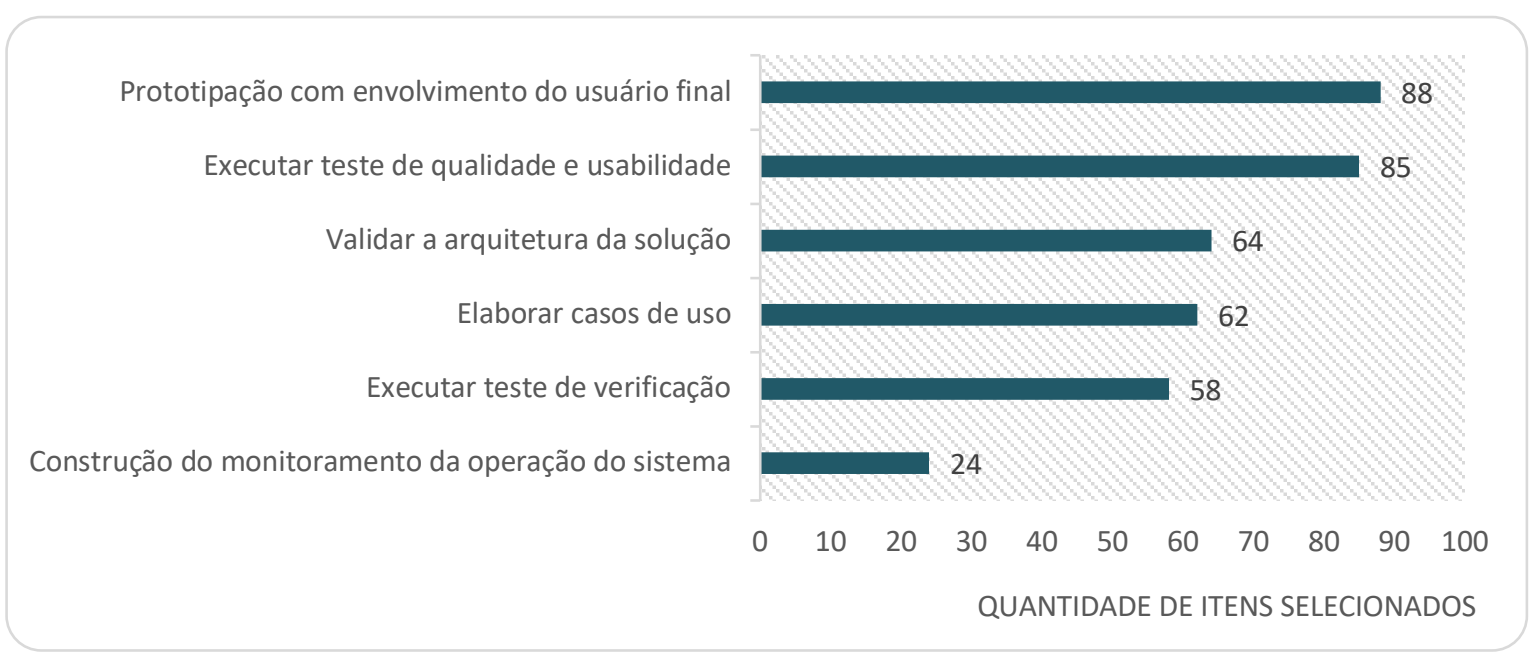

Gráfico 08: Importante para a execução da demanda Fonte: Os autores (2020)

Durante a execução da demanda, 88 respondentes consideram importante a prototipação com envolvimento do usuário final, seguida por 85 ficou a opção de testes de qualidade e usabilidade. Na próxima questão, foi questionado sobre o que não pode faltar antes da entrega do sistema, o gráfico 09 ilustra os resultados.

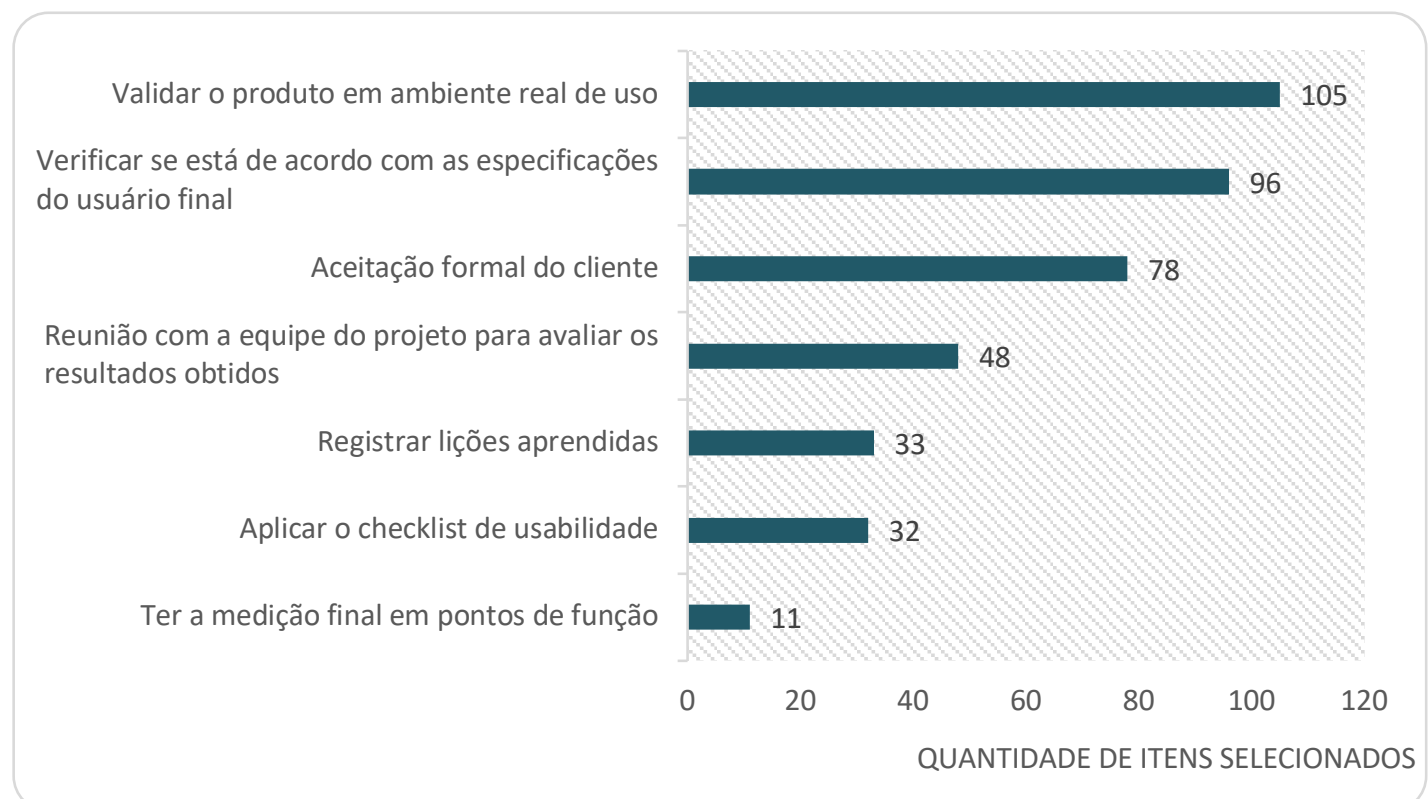

Gráfico 09: Importante antes da entrega do produto Fonte: Os autores (2020)

A opção validar o sistema em um ambiente real de uso foi selecionada por 105 respondentes, e na sequência, para 96, antes de entregar o sistema verificam se está condizente com as especificações do usuário final. 
O próximo questionamento era sobre as informações reais do público-alvo (quem vai usar o sistema) durante o atendimento da demanda. Os resultados podem ser observados no gráfico 10.

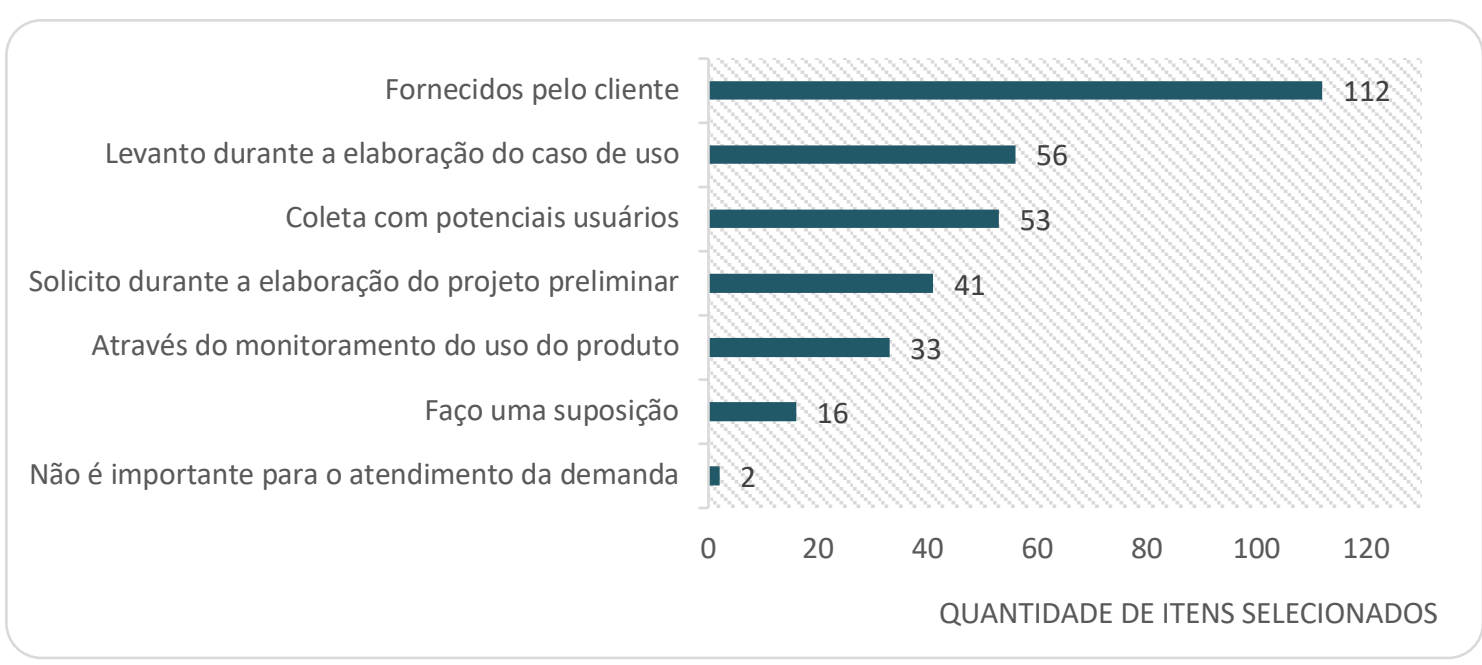

Gráfico 10: Informações reais do usuário

Fonte: Os autores (2020)

Para 112 respondentes as informações dos usuários são fornecidas pelo cliente (demandante), 56 buscam durante o caso de uso e 53 coletam com potenciais usuários, porém 16 respondentes fazem suposições.

Durante o seminário da PA em que eram discutidos os resultados, os integrantes mencionaram, por vivência interna, que a equipe de projeto recebe as informações do usuário através do cliente, ou seja, o envolvimento do usuário no PDS estaria no nível para o usuário e informativo, entendendo que as informações repassadas pelo cliente são dados de usuários reais (ex.: cidadãos). No gráfico 11, pode ser observado o que é considerado relevante na validação do sistema.

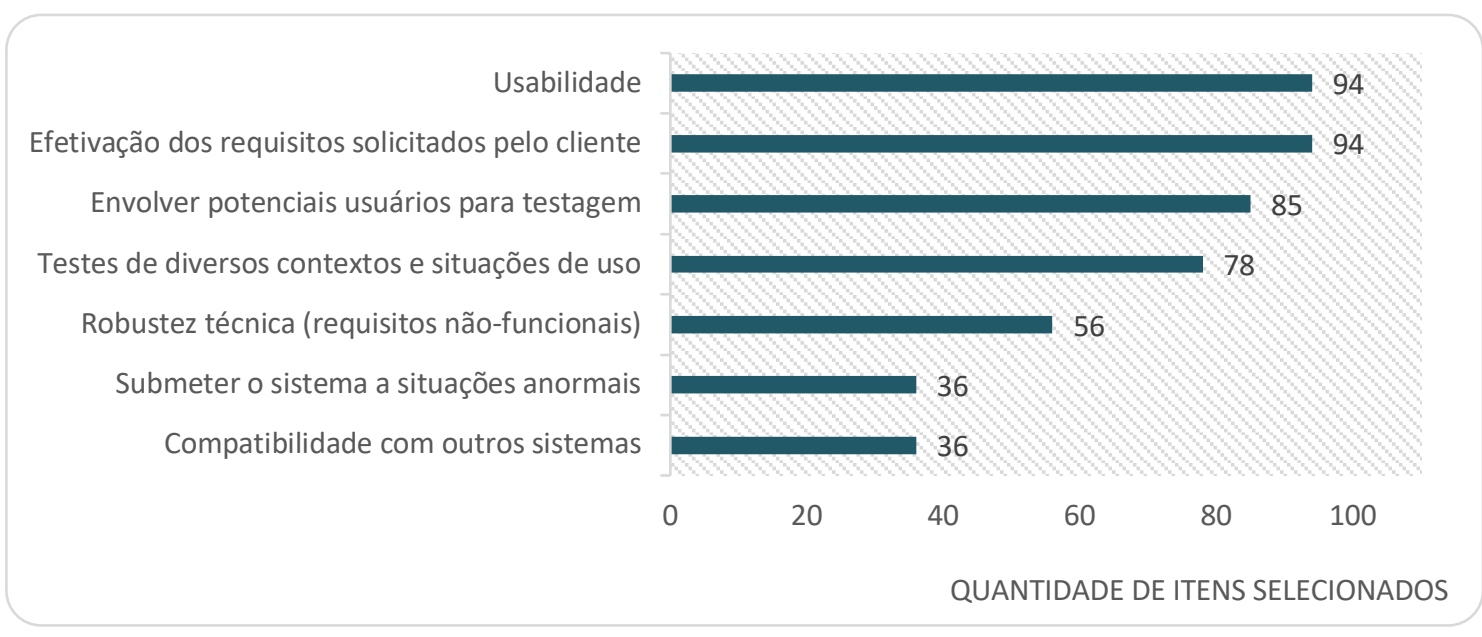

Gráfico 11: Importante para a validação do sistema Fonte: Os autores (2020)

$\mathrm{Na}$ validação do sistema, a usabilidade e a efetivação dos requisitos do cliente foram as duas opções mais selecionadas (94). Os itens que envolvem testes foram selecionados por mais da metade dos respondentes.

No que diz respeito aos questionamentos sobre o fluxo do PDS feito na organização, o PDS começa no atendimento da demanda e finaliza-se na validação do sistema. Com isso, a partir da análise dos resultados, foi possível inferir que os usuários finais ganharam importância a partir do planejamento (identificar as 
necessidades), e manteve-se presente durante a execução (prototipação e realização de testes), antes da entrega do produto (validar em ambiente real e verificação com as especificações do usuário final) e agora, na validação do sistema (usabilidade e envolver potenciais usuários para testagem).

Diante desse cenário, o nível de envolvimento do usuário no PDS pode ser caracterizado da seguinte forma: no início do PDS seria para o usuário e informativo, quando o sistema apresentar uma versão, um protótipo, o nível de envolvimento altera, sendo com ou pelo usuário e consultivo. A próxima questão estava relacionada com as causas para realizar correções no sistema (ex.: bug). O gráfico 12 representa os resultados.

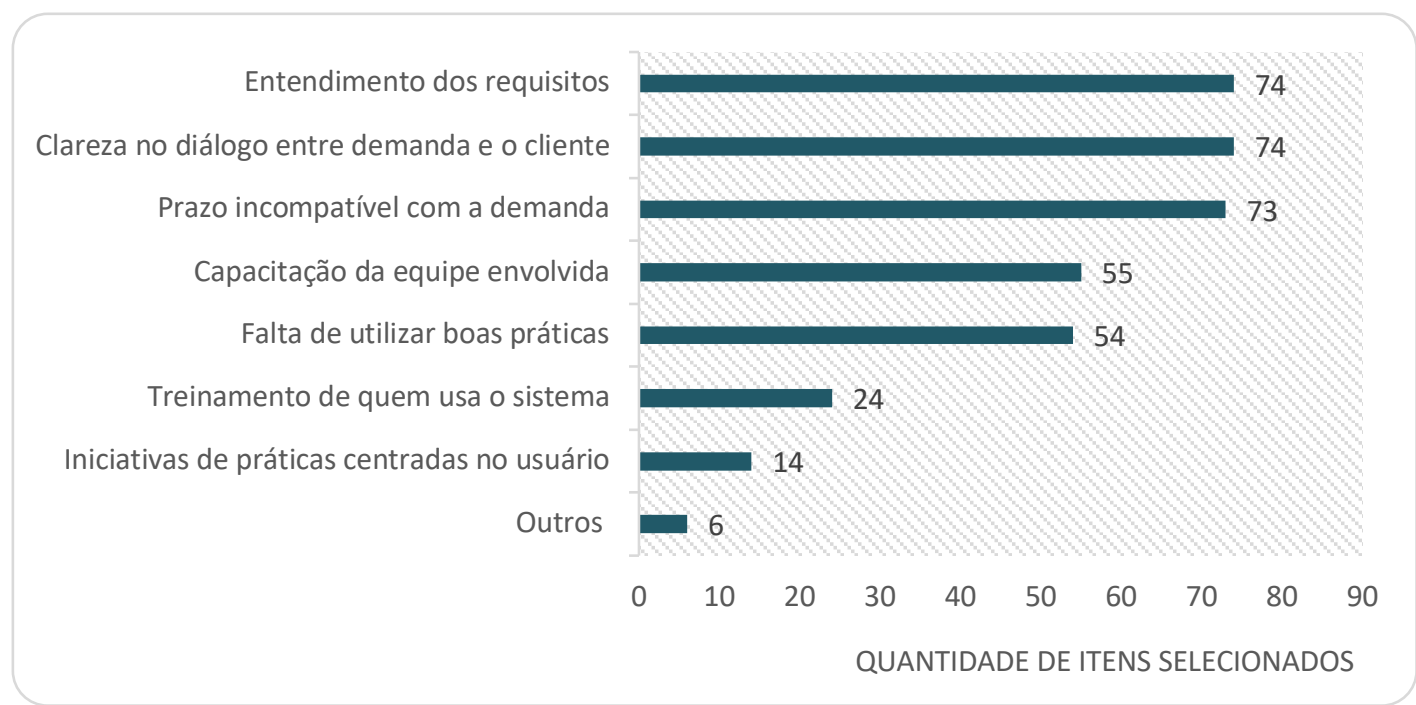

Gráfico 12: Causas de correções no sistema

Fonte: Os autores (2020)

Segundo 74 respondentes a falta de entendimento dos requisitos e a clareza na comunicação entre o projeto e o cliente são as principais causas para corrigir os sistemas. Muito próximo ficou o prazo para desenvolver o sistema (73). Apenas 14 selecionaram a falta de iniciativas de práticas centradas no usuário. A questão seguinte era para selecionar os principais motivos de reclamações geradas durante o PDS, no gráfico 13 estão sintetizados os resultados.

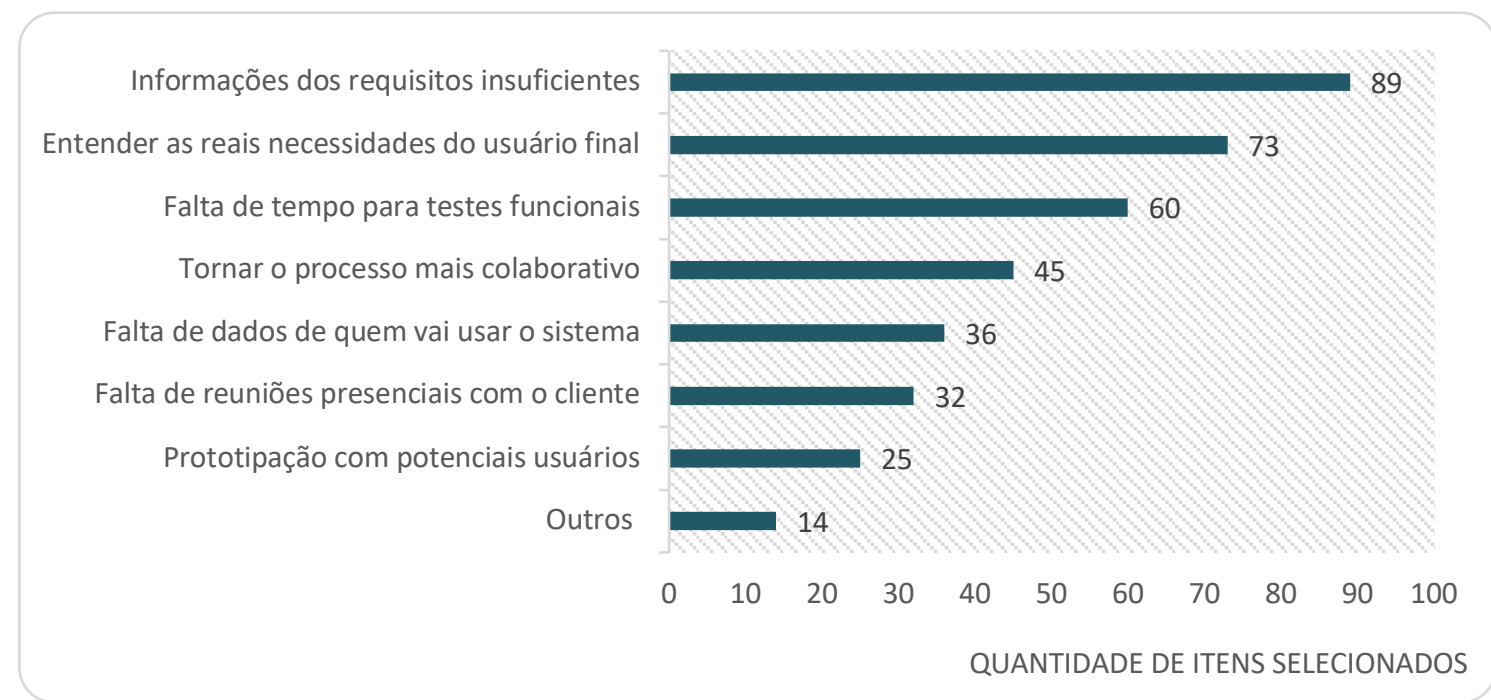

Gráfico 13: Motivos de reclamações durante o PDS

Fonte: Os autores (2020) 
Para 89 respondentes as reclamações surgem por insuficiência das informações sobre os requisitos. Destaque também para a falta de entendimento das reais necessidades do usuário final (73) e a falta de tempo para os testes (60). Os dados de quem vai usar o sistema e a prototipação com potenciais usuários não foram selecionados nem pela metade dos respondentes.

As discussões feitas entre os integrantes da PA sobre correções e reclamações, prevaleceu o assunto sobre a baixa seleção feita pelos respondentes do item falta de iniciativas centradas no usuário como causa de correções do sistema (apenas 14 selecionaram). Porém, nas reclamações a falta de entendimento das reais necessidades dos usuários finais e tempo para realizar testes receberam um número considerável de seleção.

Outro apontamento foi perante os requisitos insuficientes que geram reclamações, nas discussões do seminário os integrantes da PA chegaram na conclusão, por vivência interna, que os motivos podem ser por falha da comunicação, portanto, deve ser mais precisa, clara e eficaz no PDS, além de ter uma equipe mais entrosada e capacitada. Como também, a menção de utilização de terceiros no PDS pode comprometer a qualidade e robustez técnica gerando correções e reclamações.

As últimas quatro questões estavam focadas no DCU. Na próxima questão os desenvolvedores selecionavam a definição de DCU segundo o próprio entendimento deles. O gráfico 14 demostra os resultados.

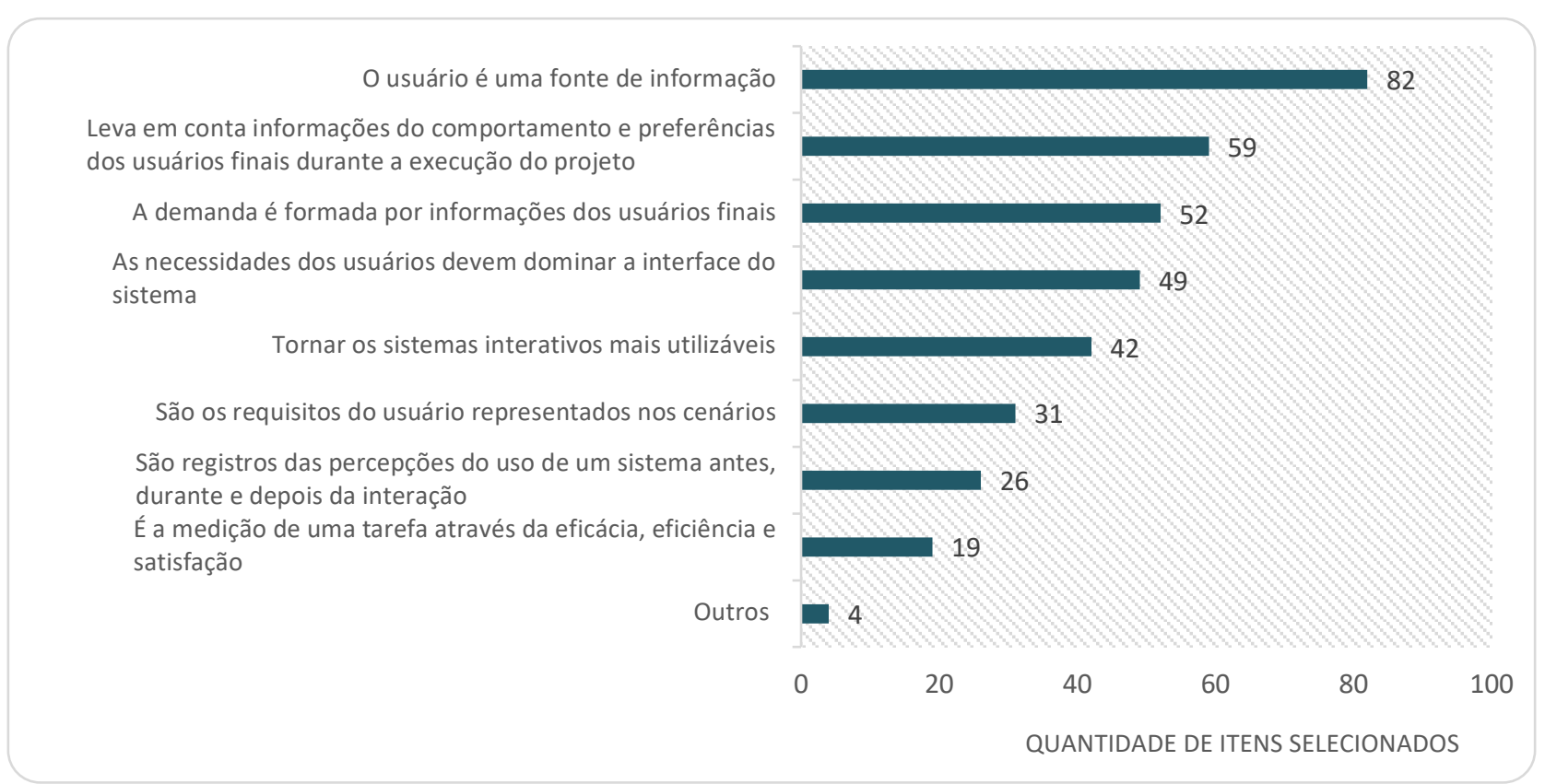

Gráfico 14: Definindo o DCU

Fonte: Os autores (2020)

As opções que foram mais selecionadas pelos respondentes condizem com a conceituação do DCU. Porém, existe a seleção de alguns itens que não representam o DCU, mas sim técnica de uso (31), UX (26) e usabilidade (19).

A próxima questão era direcionada para os desenvolvedores que consideravam a utilização do DCU, para tanto, deveriam selecionar os motivos que levavam a utilizar o DCU durante o PDS. No gráfico 15 estão sintetizados os resultados. 
Minimiza o risco do sistema não atingir requisitos que atendam os usuários finais

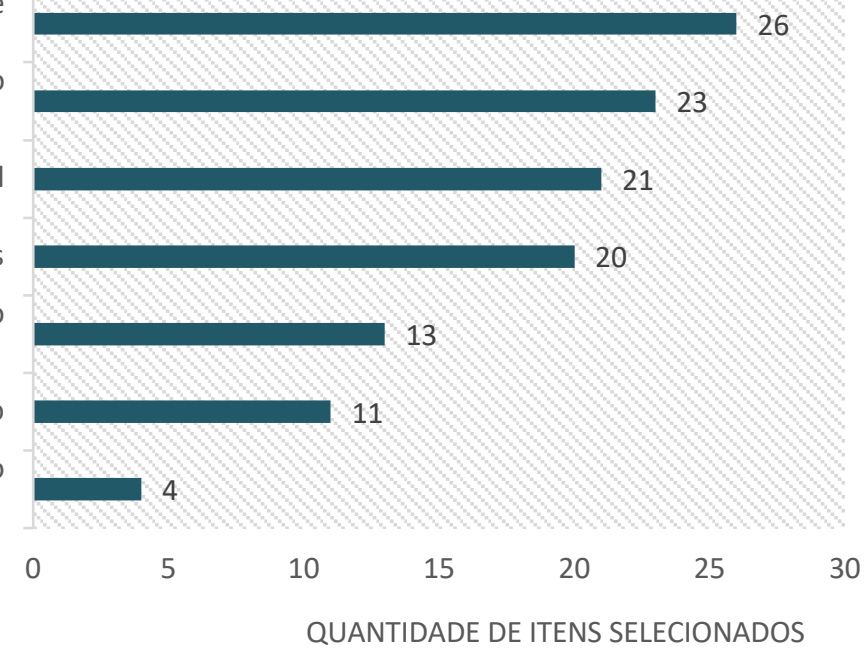

Impacta positivamente envolver o usuário final durante o projeto

Reflete as necessidades e objetivos do usuário final

Ajuda a evitar equívocos e erros

Reduz o tempo de treinamento e a necessidade de apoio para ensinar a mexer no sistema

Produz menos reprojeto

Como uma ferramenta de apoio para se ter dados do usuário final no projeto

Gráfico 15: Motivos para utilizar o DCU durante o PDS

Fonte: Os autores (2020)

Dos 122 respondentes, apenas 35 responderam essa questão. Dos itens selecionados, 26 consideram que a utilização do DCU minimiza o risco do sistema não atingir os requisitos dos usuários finais. Após a seleção, também foi pedido para justificar entre os selecionados o que o desenvolvedor considerava mais relevante.

Dos 35 respondentes, houve 17 justificativas. Das 17 justificativas, não houve um destaque, mas para 3 respondentes o mais relevante foi o item: ajuda a evitar equívocos e erros, e 2 optaram pelo item: minimiza o risco do sistema não atingir requisitos que atendam os usuários finais.

Aos respondentes que não utilizavam o DCU, foram convidados a responder os motivos pelo qual não utilizam, o gráfico 16 ilustra os resultados.

Falta conhecimento sobre o design centrado no usuário

Falta de treinamento para saber inserir o design centrado no usuário no projeto

Impacta no prazo de entrega do projeto

As informações repassadas pelo cliente sobre o usuário final são suficientes

Dificuldade em mensurar o impacto do design centrado no usuário

Outros

É um fator de risco para o processo de desenvolvimento do sistema

O checklist de usabilidade preenche a necessidade de entender o usuário final

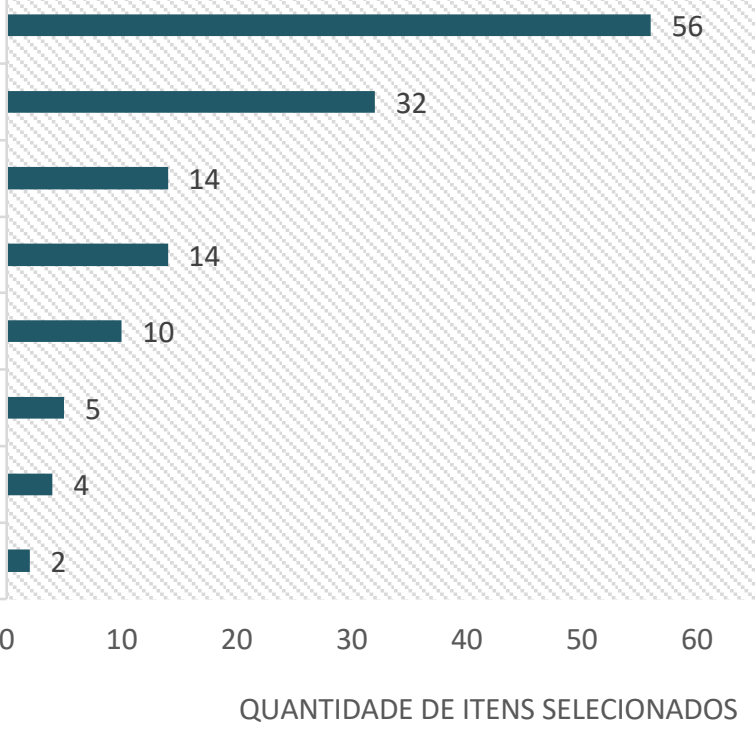

Gráfico 16: Motivos para não utilizar o DCU durante o PDS

Fonte: Os autores (2020) 
Dos 122 respondentes, 78 responderam à questão. A maioria dos respondentes selecionou o item: falta de conhecimento (56), seguindo por falta de treinamento (32). Das justificativas, houve apenas 27 inserções dos 78 respondentes. $\mathrm{O}$ item falta de conhecimento foi selecionado por 13, e 5 selecionaram a falta de treinamento.

Na última questão os respondentes foram convidados a escolher possíveis formas de inserção das práticas do DCU durante o PDS. Nesta questão não foi considerado se os respondentes tinham conhecimento conceitual, mas sim operacional, por vivência prática a que melhor se encaixava no seu dia a dia de desenvolvimento. $O$ gráfico 17 representa o resultado.

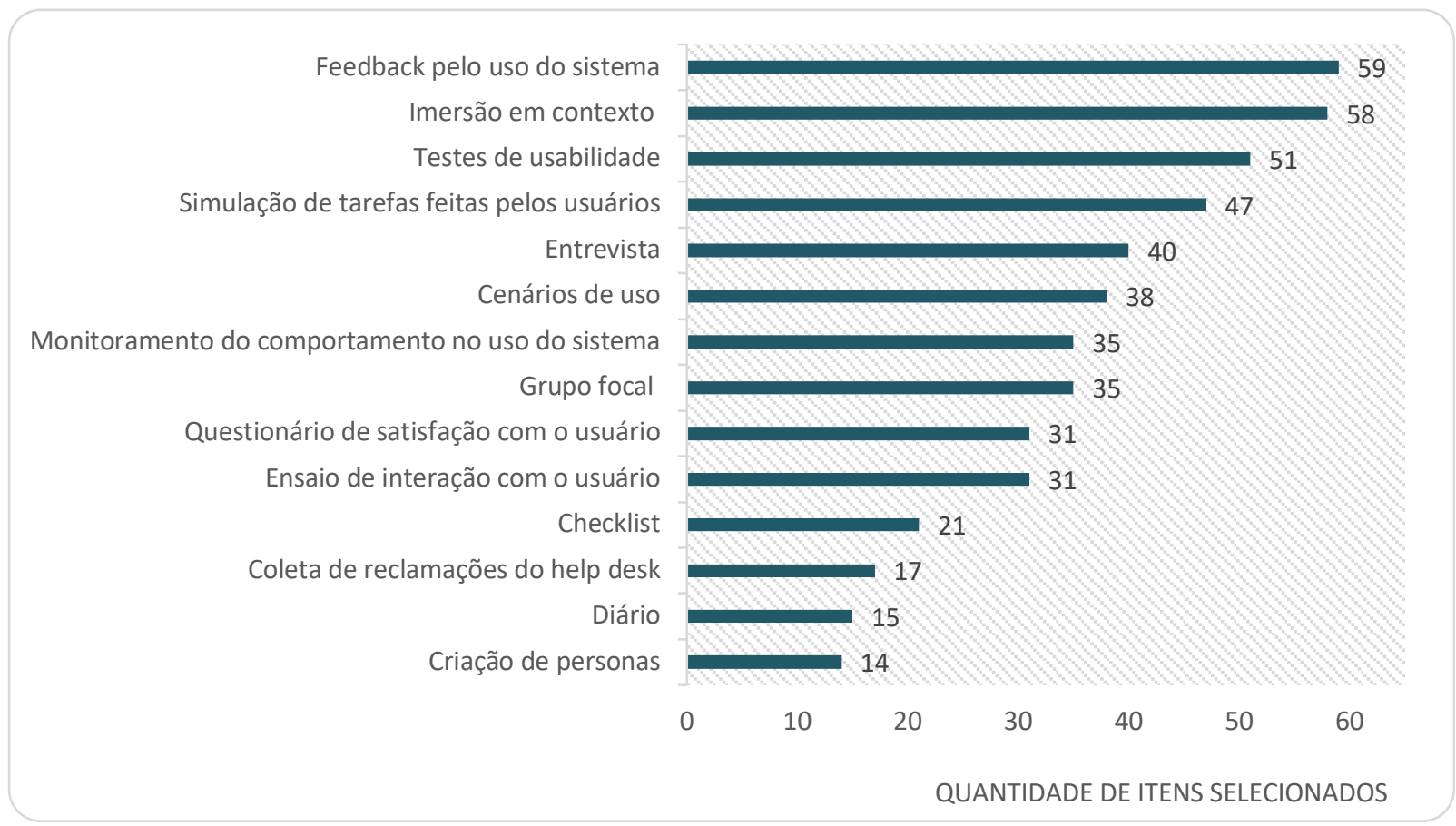

Gráfico 17: Forma de inserção do DCU durante a demanda

Fonte: Os autores (2020)

Para os 122 respondentes prevaleceu o envolvimento do usuário após o uso do sistema (59), seguido pela imersão em contexto (58), e próximo ficou os itens testes de usabilidade (51) e simulações de tarefas (47).

Das questões focadas no DCU, os integrantes da PA discutiram sobre o baixo volume de respostas que correlacionavam o termo DCU com usabilidade, UX ou técnicas (cenários de uso), considerado como um ponto positivo do levantamento. Um dos destaques comentados foi a ênfase na falta de conhecimento (56) ou de treinamento (32), situação pela qual pode movimentar novas ações da PA.

Além disso, ao analisar o gráfico 17 (formas de inserção) para 59 respondentes o envolvimento do usuário só ocorre quando o sistema estiver pronto para o uso, fornecendo o feedback, nesse sentido, o nível de envolvimento poderia ser pelo usuário e consultivo, mesma situação para a simulação de tarefas (47), ou então, com o usuário e consultivo, que também pode ser considerado nas situações de imersão em contexto (58), testes de usabilidade (51) e entrevistas (40).

Com base nos resultados da primeira ação definida pelos integrantes da PA, que constituía em realizar um mapeamento das experiências prévias dos desenvolvedores em relação ao DCU durante o PDS e-Gov na organização, foi possível elaborar uma síntese de acordo com as respostas que tiveram um volume considerável de seleção, com isso, a visão geral permite uma dimensão relacional dos momentos em que as práticas de DCU são consideradas relevantes, e estão sintetizadas na figura 02. 

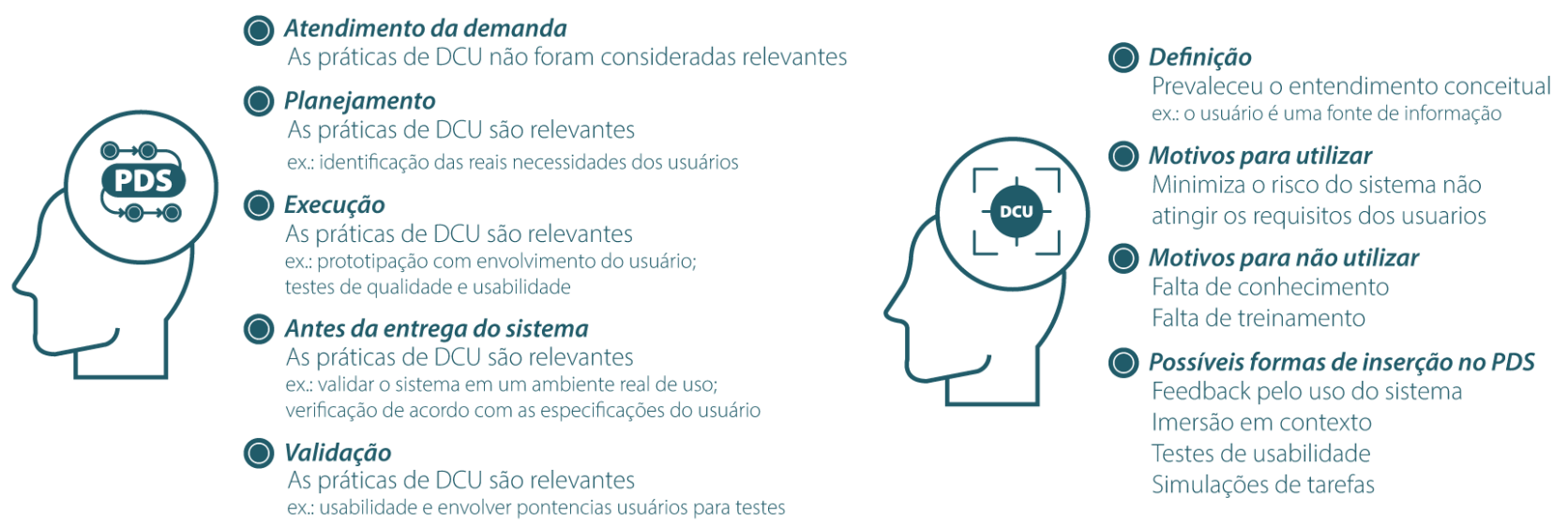

Figura 02: Visão geral da relação entre as práticas de DCU + PDS

Fonte: Os autores (2020)

\section{Considerações Finais}

O recorte de um projeto de pesquisa apresentado neste artigo teve como objetivo mapear as experiências prévias dos desenvolvedores em relação ao DCU durante o PDS e-Gov, em comum acordo com os integrantes da PA, o objetivo preencheu as necessidades iniciais da primeira ação vinculada a PA, deste modo, sua avaliação foi positiva e serve como base para a elaboração de novas ações que buscam concretizar a inserção do DCU no PDS da organização.

O resultado apresentado pelo mapeamento e em contraste com a literatura consultada, permitiu algumas reflexões finais. A critério da equipe de projeto, recomenda-se que esteja alinhada, ciente e comprometida com o envolvimento do usuário no PDS; em uma abordagem de DCU, os usuários devem estar envolvidos em todo o projeto, e de acordo com a literatura, os desenvolvedores precisam realizar simulações, elaboração de protótipos para aplicar testes com os usuários, pois os feedbacks sobre desempenho e reações colaboram no melhoramento ou validação do sistema em desenvolvimento.

Na revisão de literatura tanto os autores relatados na introdução quanto Pressman e Maxim (2015) e Sommerville (2016) que são da área de Engenharia de Software, foi possível identificar a falta de menção da área de Design, especificamente na abordagem do DCU. Portanto, com base nessas referências, é possível inferir que a formação dos desenvolvedores de sistemas e a falta de capacitação para os mesmos pode ser uma barreira para a inserção do DCU no PDS.

Durante as discussões feitas entre os integrantes da PA, notou-se que a questão condizente com uma comunicação mais clara e precisa durante o PDS recebeu uma considerável ênfase nas argumentações. Tanto que proporcionou uma possível solução, realizar uma mobilização interna na organização e desenvolver um material informativo-comunicacional sobre a abordagem do DCU, resultando em um entendimento alinhado e unificado por todos sobre o tema. Os integrantes da PA consideraram como uma futura ação do projeto.

Além disso, os integrantes da PA discutiram que as respostas trazem uma contribuição em que os desenvolvedores podem já utilizar o DCU sem saber, pela falta de conhecimento no assunto. Outro aspecto condiz com a vivência do ambiente de trabalho, questões de implementação do sistema ou tempo hábil são possíveis fatores que levam os desenvolvedores a optarem por não utilizar uma abordagem de DCU.

Das limitações do estudo, existem possíveis interpretações feitas pelos desenvolvedores perante o termo usuário-final, ou seja, pode ser compreendido por demandante (cliente, solicitante). Como também, as 
respostas podem ter sido direcionadas para o que os desenvolvedores consideram importante, relevantes, o que não significa que são usadas ou aplicadas no seu dia a dia de trabalho.

Recomenda-se para estudos futuros replicar o mapeamento em outras organizações que desenvolvem sistemas e-Gov, para avançar nos estudos focados em quem desenvolve os sistemas e suas relações práticas com o DCU.

\section{Referências Bibliográficas}

ARGANDOÑA, A. The New Economy: Ethical Issues. Journal of Business Ethics, 44, p. 03-22, 2003.

ASSOCIAÇÃO BRASILEIRA DE NORMAS TÉCNICAS. ABNT NBR ISO 9241-210: Ergonomia da interação humano-sistema Parte 210: Projeto centrado no ser humano para sistemas interativos. Rio de Janeiro: ABNT, 2011.

BARBIER, R. A pesquisa-ação. Série Pesquisa v. 3. Brasília: Liber Livro Editora, 2007.

BRASIL. Ministério do Planejamento, Desenvolvimento e Gestão. Estratégia de Governança Digital: Transformação Digital - cidadania e governo/ Ministério do Planejamento, Desenvolvimento e Gestão, Secretaria de Tecnologia da Informação e Comunicação. Brasília: MP, 2018.

CGI.br - COMITÊ GESTOR DA INTERNET NO BRASIL. Pesquisa sobre o uso das tecnologias de informação e comunicação no setor público brasileiro: TIC governo eletrônico 2015. Coordenação executiva e editorial: Alexandre F. Barbosa. São Paulo: Comitê Gestor da Internet no Brasil, 2016.

CHEVERS, D. A.; GRANT, G. Developers views on information systems quality and success in canadian software development firms. Journal of Information Systems and Technology Management, v. 14, n. 1, p. 03-20, 2017.

COUGHLAN, P; COUGHLAN, D. Action research for operations management. International Journal of Operations \& Production Management, v. 22, n. 2, p. 220-240, 2002.

CYBIS, W.; BETIOL, H. A.; FAUST, R. Ergonomia e Usabilidade: conhecimentos, métodos e aplicações. $3^{\mathrm{a}}$ ed. São Paulo/SP: Novatec. 2015.

DAMIAN, I. P. M.; MERLO, E. M. Uma análise dos sites de governos eletrônicos no Brasil sob a ótica dos usuários dos serviços e sua satisfação. Rev. Adm. Pública, Rio de Janeiro 47 (4), p. 877-99, jul./ago. 2013.

DAMODARAN, L. User involvement in the systems design process-a practical guide for users, Behaviour \& Information Technology, 15:6, p. 363-377, 1996.

DE MELO, E. R. P.; GOMES, A. O. Proposta de avaliação de portais públicos: aplicação em portais da justiça estadual no Brasil. Universitas Gestão e TI, Brasília, v. 6, n. 1, p. 109-122, jan./jun. 2016.

FREIRE, F. R.; BATISTA, C. M. Como o cidadão avalia o Portal? Um estudo com os usuários do Portal da Transparência do Governo Federal. Rev. da CGU, Brasília 8 (13), p. 373-403, jul./dez. 2016.

GOULD, J. D.; LEWIS, C. H. Designing for usability: Key principles and what designers think, Communications of the ACM 28 (3), p. 300-311, mar. 1985. 
GRÖNLUND, Åke. Electronic government: design, applications and management. Hershey, Pensilvânia: Idea Group Publishing, 2002.

GRÖNLUND, Å; HORAN, T. A. Introducing e-Gov: History, Definitions, and Issues. Communications of the Association for Information Systems: v. 15, Article 39, 2005.

GULLIKSEN, J. et al. Key principles for user-centred systems design. Behaviour and Information Technology, 22:6, p. 397-409, 2003.

JACKMAN, M. Homeopathic Remedies for Team Toxicity. IEEE Software, v. 15, n. 4, p. 43-45, 1998.

JUDICE, A. C. B. et al. A experiência do usuário de serviços do governo: mapeamento com base em abordagens centradas no cidadão. Relatório fornecido pela Information Technology - Research and Application Center (ITRAC). Universidade de Brasília - Faculdade UnB Gama, Brasília - DF, 2019.

KRINNER, C. How Developers Anticipate User Behavior in the Design of Assistance Systems. In: HARRIS, D. (ed.). Engineering Psychology and Cognitive Ergonomics. EPCE 2007. Lecture Notes in Computer Science, Springer, Berlin, Heidelberg, v. 4562, 2007, p. 98-107.

LINDBERG, T.; MEINEL, C.; WAGNER, R. Design Thinking: A Fruitful Concept for IT Development? In: PLATTNER, H.; MEINEL, C.; LEIFER, L. (ed.). Design Thinking: Understand - Improve - Apply. Springer-Verlag Berlin Heidelberg, 2011, p. 03-18.

MULLER, M. J.; DRUIN, A. Participatory Design: The Third Space in Human-Computer Interaction. In: JACKO, J. A. (ed.). The Human-Computer Interaction Handbook Fundamentals, Evolving Technologies, and Emerging Applications. $3^{\text {a }}$ ed. Taylor \& Francis Group - CRC Press, 2012.

NORMAN, D. A. O design do dia-a-dia. Rio de Janeiro: Rocco, 2006.

NORMAN, D. A. e DRAPER S. W. User Centered System Design: New Perspectives on HumanComputer Interaction. Software Quality Institute series. New Jersey: Lawrence Erlbaum Associates, 1986.

OECD - Organisation for Economic Co-operation and Development. The e-Government Imperative. OECD e-Government Studies. Paris/France: OECD Publishing, 2003.

PRESSMAN, R. S.; MAXIM, B. Software Engineering: A Practitioner's Approach. $8^{\mathrm{a}}$ ed. New York: McGraw-Hill Education, 2015.

SÁNCHEZ-TORRES, J. M.; MILES, I. The role of future-oriented technology analysis in e-Government: a systematic review. European Journal of Futures Research 5:15, 2017.

SOMMERVILLE, I. Software Engineering. 10ª ed. Harlow, Inglaterra: Pearson Education, 2016.

STRINGER, E. T. Action research. $3^{\text {a }}$ ed. Thousand Oaks, Califórnia: Sage Publications, 2007.

SUSMAN, G. I.; EVERED, R. D. An Assessment of the Scientific Merits of Action Research. Administrative Science Quarterly, v. 23, n. 4, p. 582-603, dez. 1978.

THIOLLENT, M. Metodologia da pesquisa-ação. 18a ed. São Paulo: Cortez, 2011.

TRIPP, D. Pesquisa-ação: uma introdução metodológica. Educação e Pesquisa, v.31, n.3, p. 443-466, 2005. 


\section{Agradecimentos}

O presente trabalho foi realizado com apoio da Coordenação de Aperfeiçoamento de Pessoal de Nível Superior - Brasil (CAPES) - Código de Financiamento 001. 